\title{
Age of Drinking Onset, Driving After Drinking, and Involvement in Alcohol-Related Motor Vehicle Crashes
}


This publication is distributed by the U.S. Department of Transportation, National Highway Traffic Safety Administration, in the interest of information exchange. The opinions, findings and conclusions expressed in this publication are those of the author(s) and not necessarily those of the Department of Transportation or the National Highway Traffic Safety Administration. The United States Government assumes no liability for its content or use thereof. If trade or manufacturer s names or products are mentioned, it is because they are considered essential to the object of the publication and should not be construed as an endorsement. The United States Government does not endorse products or manufacturers. 


\begin{tabular}{|c|c|c|c|c|}
\hline & \multicolumn{2}{|c|}{ 2. Govemment Accession No. } & \multicolumn{2}{|c|}{ 3. Recipient's Catalog No. } \\
\hline \multirow{2}{*}{\multicolumn{3}{|c|}{$\begin{array}{l}\text { 4. Tritle and Subtitie } \\
\text { Age of Drinking Onset, Driving After Drinking, and Involvement in } \\
\text { Alcohol-Related Motor Vehicle Crashes }\end{array}$}} & \multicolumn{2}{|l|}{$\begin{array}{l}\text { 5. Report Date } \\
\text { January } 2001\end{array}$} \\
\hline & & & \multicolumn{2}{|c|}{$\begin{array}{l}\text { 6. Performing Organization Code } \\
\text { NTS-31 }\end{array}$} \\
\hline \multicolumn{3}{|c|}{$\begin{array}{l}\text { 7. Author(s) } \\
\text { Hingson, R., Sc.D.; Heeren, T., Ph.D.; Levenson, S., M.Ed., M.P.H. } \\
\text { Jamanka, A., M.P.H.; Voas, R. Ph.D. }\end{array}$} & \multicolumn{2}{|c|}{ 8. Performing Organization Report No. } \\
\hline \multicolumn{3}{|c|}{$\begin{array}{l}\text { 9. Performing Organization Name and Address } \\
\text { Social and Behavioral Sciences Department } \\
\text { Boston University School of Public Health } \\
715 \text { Albany Street, T 2W } \\
\text { Boston, Massachusetts } 02118\end{array}$} & \multicolumn{2}{|c|}{ 10. Work Unit No. (TRAIS) } \\
\hline \multicolumn{3}{|c|}{$\begin{array}{l}\text { 12. Sponsoring Agency Name and Address } \\
\text { National Highway Traffic Safety Administration } \\
\text { Office of Program Development and Evaluation } \\
400 \text { 7th Street, S.W., Washington, DC } 20590\end{array}$} & \multicolumn{2}{|c|}{ 14. Sponsoring Agency Code } \\
\hline \multicolumn{5}{|c|}{ 15. Supplementary Notes } \\
\hline \multicolumn{5}{|c|}{$\begin{array}{l}\text { This study assessed whether persons who begin drinking at younger ages are more likely to report drunk } \\
\text { driving and alcohol-related crash involvement over the life course, even after controlling analytically for } \\
\text { diagnosis of alcohol dependence and other personal characteristics associated with the age respondents started } \\
\text { drinking. A national survey conducted for the National Institute on Alcohol Abuse and Alcoholism in } 1992 \text {, } \\
\text { asked } 42,862 \text { respondents the age they started drinking, whether they drove after drinking too much, and } \\
\text { whether they were in motor vehicle crash(s) because of their drinking. The current study found that, the } \\
\text { earlier the age respondents started drinking, the more likely they were to report driving after drinking too } \\
\text { much and being in a motor vehicle crash because of their drinking, even after adjusting for current/ever } \\
\text { diagnosis of alcohol dependence and other characteristics and behaviors associated with the age respondents } \\
\text { started drinking. Even among persons who were never alcohol dependent, those who began drinking in each } \\
\text { age group under } 21 \text {, relative to those starting at age } 21 \text { or older, were more likely to report "ever" and "in the } \\
\text { past year" being in a crash after drinking too much. The traffic safety benefits of delaying drinking may } \\
\text { extend well beyond the legal drinking age of } 21 \text {. }\end{array}$} \\
\hline \multicolumn{2}{|c|}{$\begin{array}{l}\text { 17. Key Words } \\
\text { alcohol, drinking onset, driving after drinking, } \\
\text { motor vehicle crashes }\end{array}$} & \multicolumn{3}{|c|}{$\begin{array}{l}\text { 18. Distribution Statement } \\
\text { This report is available from the National Technical Information } \\
\text { Service, Springfield, Virginia } 22161 \text { (703) } 605-6000 \text {. It is also } \\
\text { available, free of charge, on the NHTSA web site at } \\
\text { www.nhtsa.dot.gov }\end{array}$} \\
\hline $\begin{array}{l}\text { 19. Security Classif. } \\
\text { (of this report) }\end{array}$ & $\begin{array}{l}20 . \\
\text { (of t }\end{array}$ & lassif. & $\begin{array}{l}\text { 21. No. of } \\
\text { Pages }\end{array}$ & 22. Price \\
\hline
\end{tabular}




\section{ACKNOWLEDGEMENTS}

The National Longitudinal Alcohol Epidemiology Study (NLAES) was sponsored by the National Institute on Alcohol Abuse and Alcoholism (NIAAA). We would like to thank Dr. Bridgett Grant at NIAAA for her help on this project. The National Highway Traffic Safety Administration (NHTSA) sponsored the data analysis for this paper. 


\section{INTRODUCTION}

To reduce alcohol-related fatal crashes among youth, all states have adopted a minimum legal drinking age (MLDA) of 21. States adopting MLDAs of 21 in the early 1980 s experienced a 10 - 15 percent decline in alcohol-related traffic deaths among drivers in the targeted ages compared with states that did not adopt such laws (General Accounting Office, 1987). The National Highway Traffic Safety Administration (NHTSA) has estimated that the MLDA of 21 prevents 700-1,000 traffic deaths annually among persons under 21, and that over 18,000 traffic deaths among persons under 21 have been prevented since 1975 (National Highway Traffic Safety Administration, 1999).

MLDA laws not only decreased drinking among persons under age 21 , they also lowered drinking among people age 21 to 25 who grew up in states with MLDAs of 21 relative to those who grew up in other states (O'Malley \& Wagenaar, 1991). However, it is not known whether these laws, and other efforts to reduce underage drinking, lower both driving after drinking and alcohol-related motor vehicle crash involvement later in life.

A recent analysis of the National Longitudinal Alcohol Epidemiologic Survey (NLAES) found that age of drinking onset was strongly related to having experienced alcohol dependence during one's life as defined by the diagnostic criteria of the Diagnostic and Statistical Manual, Fourth Edition (DSM-IV) (American Psychiatric Association, 1994). Among both males and females and persons with and without a family history of alcoholism, persons who began drinking regularly before age 14 were at least 3 times more likely than those who did not drink alcohol until they were over age 21 to experience diagnosable alcohol dependence during their life (Grant, 1998). Questions in that survey permit us to explore whether age of drinking onset is similarly related to whether respondents, ever in their life, and specifically during the year prior to the survey, reported having:

- driven a motor vehicle after having too much to drink; and

- been in a motor vehicle crash because of their drinking Independent of factors such as alcohol dependence that are related to early age of drinking onset.

\section{METHOD}

The National Longitudinal Alcohol Epidemiologic Survey (NLAES) was a national probability survey sponsored by the National Institute on Alcohol Abuse and Alcoholism. In 1992, the U.S. Bureau of the Census administered face to face interviews with 42,862 respondents age 18 and older, mean age 44 , residing in the noninstitutionalized population of the contiguous states including the District of Columbia. Sample Design:

The multi-stage sampling approach used for NLAES was described by Massey et. al., (1989). Primary sampling units (PSUs) were stratified according to socioeconomic criteria and were selected with a probability proportional to their population size. Within PSUs, geographically defined secondary sampling units, referred to as segments, were selected systematically for the sample. The African American population was oversampled at this stage of the sample selection to secure adequate numbers for analytic purposes. Segments were then divided into clusters of 4-8 housing units, and all 
occupied housing units were included in the survey. Within each household, one randomly selected person age 18 and older was selected to participate. Young adults age 18-29 were oversampled at a ratio of 2.25:1.00 at this stage of sample selection to include a greater representation of this heavier drinking population subgroup. Weighting using SUDAAN (Shah, 1996) adjusted for the deliberate oversampling of African American and persons age 18-29 and accounted for the complex sampling design of NLAES. The household response rate for this representative sample of the U.S. population was $91.9 \%$ and the sample person response rate was $97.4 \%$. The overall response rate was $90 \%$. (A longitudinal follow up was initially planned but not completed because of financial constraints. A repeat cross sectional survey is currently being considered).

\section{Outcome measures}

Driving after drinking was explored by asking respondents, "In your entire life, did you ever drive a car, motorcycle, truck or boat, or other vehicle after having too much to drink? Did that happen in the past 12 months?" Alcohol-related crash involvement was explored by asking respondents, "In your entire life, did you ever have a car, motorcycle, truck, boat, or other accident because of your drinking? Did that happen in the past 12 months?"

\section{Predictor Variables}

Measures of alcohol use and dependence were derived from the Alcohol Use Disorder and Associated Disabilities Interview Schedule (AUDADIS) (Grant and Hasin, 1992); a fully structured diagnostic psychiatric interview designed to be administered by trained interviewers who were not clinicians.

The age of drinking onset was ascertained by asking respondents how old they were when they first started drinking, not counting small tastes or sips of alcohol. Drinking onset data was collected from respondents who were classified as current drinkers (persons who had consumed at least 12 drinks in the past 12 months) and former drinkers (persons who had consumed at least 12 drinks in any one year of their lives but not during the year prior to the interview). Only current and former drinkers were included in the analysis. In an independent test retest study before the full NLAES was conducted, the test retest reliability of the drinking onset variable was good with a Kappa of .72 (Grant, Harford, Dawson et. al., 1995).

The definition of lifetime alcohol dependence was based on the diagnostic criteria of the Diagnostic and Statistical Manual, Fourth Edition (DSM-IV) (American Psychiatric Association, 1994). The AUDADIS interview included an extensive list of symptom questions that operationalize the DSM-IV criteria for alcohol dependence. Diagnosis of alcohol dependence required that in any one year a respondent meet at least three of the following seven criteria for dependence: 1) tolerance, 2) withdrawal or avoidance of withdrawal, 3) persistent desire or unsuccessful attempts to cut down or stop drinking, 4) spending much time drinking, obtaining alcohol, or recovering from its effects, 5) giving up or reducing occupational, social, or recreational activities in favor of drinking, 6) impaired control over drinking and 7) continuing to drink despite a physical or psychological problem caused or exacerbated by drinking. Respondents were classified as showing a life time alcohol dependence diagnosis if they experienced an episode of dependence in the past year or at any time before the past year. The 
independent test retest study determined good reliabilities with Kappas of 0.76 , and .0 .73 for past year and prior to past year dependence diagnoses respectively (Grant, Harford, Dawson et. al., 1995).

The following demographic and behavior variables were examined as potential confounders of the association between age of drinking onset and later behavior: current age, sex, race/ethnicity (white non-hispanic, black non-hispanic, hispanic, other), education, marital status, smoking status (current, former, never), illicit drug use status (current, former, never) and alcohol dependency (current, former, never).

\section{Statistical Analysis}

Like other reports of the NLAES, our statistical analyses were conducted using the SUDAAN statistical package (Shah, 1996) to account for the complex survey design and oversampling of NLAES in the estimation of both effects and their standard errors (the pattern of results was very similar with and without use of the SUDAAN weighting). We focused on respondents who reported drinking ever in their lifetime $(n=27,081)$. The univariate associations between age of drinking onset and drinking and driving outcomes and demographic and background behavior characteristics was tested using a modified test of independence that adjusts for the sampling design. The test for independence in SUDAAN is based on the Wald statistic comparing observed and expected values and follows the strategy proposed by Koch, Freeman, and Freeman (1975) for analyzing complex survey data. The p-value for this test is based on transforming the Wald Statistic to an F-statistic where degrees of freedom represent the size of the contingency table and the number of PSU's and strata in the study design. Logistic regression explored whether age of drinking onset was associated with each of the drinking and driving outcomes, controlling for potential confounding from demographic and behavior characteristics including alcohol dependency. The overall significance of the relations between different ages of drinking onset and study outcomes in the logistic models were tested through a chi-square statistic comparing models with and without the set of indicator variables representing age of onset. We examined whether the potential association between age of drinking onset and drinking and driving outcomes persisted after controlling for alcohol dependence because of the established relationships between alcohol dependence and drinking and driving and between age of drinking onset and alcohol dependency (Grant, 1998). We also examined the potential relationships between age of drinking onset and drinking and driving behavior in the subset of respondents who were never alcohol dependent $(n=21,713)$.

\section{RESULTS}

Sixty-five percent of respondents ever drank alcohol, 49 percent before age 21 and 3 percent before age 14. The mean drinking onset age was 19.0 years. Four percent were classified as alcohol dependent in the past year and 13 percent ever in their life.

Twenty-three percent of respondents reported driving a motor vehicle after having too much to drink ever in their life and five percent in the past year. Four percent of respondents reported ever having been in a motor vehicle crash because of their drinking, 0.2 percent in the past year. The earlier the age respondents began drinking, the greater the proportions who reported driving after drinking too much and motor vehicle crash involvement because of drinking ever in their lives and during the year prior to the 
survey. As can be seen in Figure 1, persons who began drinking before age 14 were 3 times more likely than those who began drinking after age 21 to report ever driving after drinking too much, 53 percent vs. 18 percent, and 4 times more likely to report doing so in the past year, 13 percent vs. 3 percent. As seen in Figure 2, respondents who began drinking before age fourteen were 7 times more likely than those who began drinking after age 21 to report ever being in a motor vehicle crash because of their drinking, 14 percent vs. 2 percent, and during the past year, 0.7 percent vs. 0.1 percent. The magnitude of differences tended to become smaller as the age of drinking onset became closer to 21. As seen in Figures 1 and 2, even after age 21, the older respondents were when they began to drink the less likely they were to drive after drinking or be in traffic crashes after drinking.

Several subgroups in the study were significantly more likely to have begun drinking at younger ages: male respondents, younger respondents, those with less than a high school education, persons never married, and persons who currently or ever smoked or used illicit drugs and respondents with a current (past year) or lifetime diagnoses of alcohol dependence (all relations $p<.001$; data available upon request).

To control for these potentially confounding characteristics, we entered those background characteristics into a series of multiple logistic regression analyses examining the following outcomes as dichotomous variables: whether or not respondents drove after drinking too much, or were in a motor vehicle crash because of their drinking. Each of these outcomes was examined ever during the respondent's life and during the year prior to the interview.

Respondents who began drinking at an earlier age were significantly more likely to report that they drove after drinking too much ever and in the past year. Further, they were significantly more likely to have ever been involved in a motor vehicle crash after drinking too much. For each study outcome, the odds ratio and $95 \%$ confidence intervals for respondents who began drinking each year from less than age 14 through 20 relative to those who began at age 21 or older was examined separately. Persons starting at age 21 and older were analyzed as a group for comparison because the minimum legal drinking age is 21 . Results are summarized in Figures 3 and 4.

The strongest relationships were observed when comparing respondents who started drinking at age 14 relative to those starting at age 21 and older. Persons who began drinking when they were age 14 were $3.4(95 \%$ CI $2.7,4.3)$ times more likely than those who began after age 21 to report ever driving after drinking too much and 2.33 (1.7, 3.2) times more likely to do so in the year prior to the survey. Further, they were 4.1 times more likely to report being in a motor vehicle crash after drinking too much ever $(95 \% \mathrm{CI} 2.9,5.8)$ and in the past year $(95 \% \mathrm{CI} 1.5,10.9)$. As can be seen in the figures, these relationships tended to be stronger for those whose age of drinking onset was younger. Also the relations were stronger when we examined whether respondents ever in their life drove after drinking too much or were ever in a motor vehicle crash because of drinking as compared with those who experienced these outcomes in the past year. Respondents who began drinking in each age group under 21 relative to those starting after age 21 were significantly more likely to report ever driving after drinking too much and ever being in a motor vehicle crash because of their drinking.

We also repeated the logistic regression analysis examining only the subgroup of respondents who drank but never experienced alcohol dependence $(n=21,462)$. Just over 
half the sample and $79 \%$ of persons who ever drank this group represented $35 \%$ of those who reported motor vehicle crashes after too much drinking ever during their life and $28 \%$ of those reporting such crashes in the year prior to the interview. Those who started drinking in each age group under 21 were significantly more likely than those who started drinking after age 21 to have ever and in the past year been in a motor vehicle crash after drinking too much. (Figure 5).

\section{DISCUSSION}

The relative risk of involvement in fatal crashes increases with increasing driver blood alcohol content and the risks increase more steeply for drivers under age 21 than for older drivers (Zador, Krawchuk and Voas, 2000). Previous studies have shown that raising the legal drinking age to 21 reduced drinking and alcohol related motor vehicle crash involvement among persons under age 21 (General Accounting Office, 1987; National Highway Traffic Safety Administration, 1999). Prior research also indicated that persons who grew up in states with a legal drinking age of 21 relative to those who grew up in states with lower legal drinking ages, not only drank less when they were under age 21 , but also when they were age 21 to 25 (O'Malley \& Wagenaar, 1991). However, it is not known whether efforts to reduce underage drinking lowers driving after drinking and alcohol related motor vehicle crash involvement later in life.

This national study of persons 18 and older, mean age 44, found that the earlier the age respondents started drinking, the more likely they were to report driving after drinking too much ever in their life and in the past year. Also the earlier the age of drinking onset, the greater the likelihood the respondents reported being in a motor vehicle crash because of their drinking, even after we analytically controlled for characteristics and behaviors associated with earlier drinking onset: whether or not respondents ever or currently had an alcohol dependence diagnosis, age, gender, education, race/ethnicity, marital status, smoking, or illicit drug use. A 4-fold increased alcohol-related crash risk for those who began drinking at age 14 relative to those who started after age 21 was found both ever-in a respondent's life and during the year of the survey suggesting the relationship may not be purely a function of having more years of alcohol exposure. Also, the relationships were not solely a function of people who start drinking at an early age being more likely to become alcohol dependent. Among persons who were never alcohol dependent, relative to respondents who started drinking at age 21 or older, those who began drinking at age 14, and in each succeeding age up through age 20 were significantly more likely to report being in a motor vehicle crash after drinking ever and during the year prior to the survey.

Several methodological factors should be considered when interpreting the study's results. First, the distribution of responses on key drinking variables was similar in the NLAES sample when compared to other large national surveys. The National Longitudinal Survey of Labor Market Experience in Youth (NLSY)(N=12,686) was a follow up study of a survey designed to represent the non institutionalized population of young people age 14-21 as well as person 17-21 serving in the military in 1979. Grant, Harford and Stinson (In Review) reported the ages respondents in that sample started drinking. Compared to respondents in the NLAES who were in those age groups in 1979 $(\mathrm{N}=4210)$ the proportion of drinkers in the NLSY who started drinking at $<14$, and each consecutive year up to age 21 and older were virtually identical (data available upon 
request). When compared to the 1998 National Health Interview study, an area probability sample of over 100,000 persons nationwide, similar proportions of the NLAES sample were classified as ever having drunk alcohol $65 \%$ vs. $71 \%$ or as having met DSM IV alcohol dependence criteria $4.4 \%$ vs. $5.9 \%$. In NLAES to be classified as ever drinking a person had to drink at least 12 drinks in a given year. In the National Alcohol Survey conducted in 1990 the proportion who met DSM IV dependence criteria was 3.9\% (for data from the National Health Interview Study and the National Alcohol Survey see U.S. Department of Health and Human Services, 1997). The proportion who drove a motor vehicle after having too much to drink in the past year 5\% in NLAES was similar to the percentage reporting they drove while impaired by alcohol in the past month 2.5\% in CDC's 1993 national Behavioral Risk Factor Survey of over 102,263 adults 18 or older (Lui et.al., 1997).

Second, even though respondents said the motor vehicle crashes they experienced were because of their drinking, it is impossible to be certain that alcohol was the sole cause of the crash. However, alcohol use was present and the crash can be considered alcohol-related.

Third questions were not asked about the amount that respondents drove in general or crash involvement when they had not been drinking. Driving amounts could have influenced the key findings of this study. Also it would be of value to assess whether age of drinking onset was more closely related to alcohol related crash involvement than involvement in crashes where alcohol was not a factor.

Fourth, questions regarding driving after drinking and motor vehicle crash involvement after drinking could have been more objectively worded. In the NLAES survey, respondents were asked if they drove after drinking too much ever and in the past year and if they were in a motor vehicle crash because of their drinking ever and in the past year. A more objective approach would have been to ask respondents if they drove or were in a motor vehicle crash within an hour after consuming a specific number of drinks. The way questions were worded in the NLAES suggests the relations observed may have been stronger than reported. Persons who drive after drinking tend to believe they can consume more drinks and still drive safely than people who do not drive after drinking (National Highway Traffic Safety Administration, 1996). Consequently, they may under report the actual frequency with which they drove after drinking or were in a crash because of their drinking.

Fifth, there is the possibility that social desirability biases may have influenced respondents. Those least likely to admit drinking at an early age may be least likely to admit driving after drinking too much and being in a motor vehicle crash because of drinking.

Sixth, the survey was cross sectional and older adults may have difficulty remembering the age they first started to drink. Finally, because the survey was confidential, efforts were not made to link self-reports of crash involvement to driver records. Longitudinal studies asking adolescents when they first began to drink with more objective questions about driving after drinking and crash involvement and which explore actual traffic records need to be conducted.

The results of this study point to a need to explore why people who start drinking at an early age are more likely to report driving after drinking in the past year even among persons who are not alcohol dependent. Several factors may contribute to the relation. 
First, it is possible that people who engage in a variety of deviant or illegal behaviors at an early age are more likely to engage in several such behaviors later in life. However, the relationships in this study between early drinking onset and driving after drinking and motor vehicle crash involvement were independent of current or past use of illegal drugs or tobacco. Second, persons who start drinking at an early age more frequently drink heavily than those who start consuming alcohol later in life even if they are not alcohol dependent (Hingson, Heeren, Jamanka, \& Howland, In Press). This could increase the likelihood that they would also drive more frequently after drinking. Also, persons who begin drinking at an early age may be less likely to believe that driving after drinking increases crash risks. They may believe for example, that the risk of traffic crashes and other injuries increase only for people who are visibly intoxicated. They may derive pleasure or a sense of self-esteem by taking driving risks. It is well known that people who drive after drinking are more likely to speed and are less likely to wear seat belts. Also, heavy consumption of alcohol may further impair the judgement of those who start drinking at an earlier age. After drinking they may be less likely to appreciate their increased crash risk than when sober. Whether those who start drinking at a younger age are as aware of traffic laws and as likely to believe those laws will be enforced also warrants exploration.

A recent report indicated that after a decade of decline, the percentage of high school seniors who drink and drive has increased the last two years ( $O^{\prime}$ Malley \& Johnston, 1999). The study reported here identifies another important reason to step up enforcement of the legal drinking age of 21 and to expand educational and community programs that delay the onset of drinking. The potential traffic safety benefits of delaying underage drinking may extend well beyond age 21 . 


\section{REFERENCES}

American Psychiatric Association. (1994) Diagnostic and Statistical Manual of Mental Disorders (DSM IV). Washington, D.C.

General Accounting Office (1987) Drinking age laws: an evaluation synthesis of their impact on highway safety. GAO PEMD 87-100, Washington, DC.

Grant B.F.; Harford T.C. and Stinson F. Age at onset of alcohol use and DSM IV alcohol abuse and dependence, a twelve-year follow up, Journal of Substance Abuse (under review).

Grant B.F., Harford F.C., Dawson D.A., Chou P.S. and Pickerling R.P. (1995) The alcohol use disorder and associated disabilities interview schedule: reliability of alcohol and drug modules in a general population sample, Drug and Alcohol Dependence. 39, $37-44$.

Grant, B. (1998) The impact of family history of alcoholism on the relationship between age at onset of alcohol use and DSM-III alcohol dependence, Alcohol Health and Research World. 22, 2, $144-147$.

Grant, B. F. and Hasin, D.S. (1992) The alcohol use disorders and associated disabilities interview schedule. National Institute on Alcohol Abuse and Alcoholism, Rockville, Maryland.

Hingson R., Heeren T., Jamanka A., and Howland J., Age of drinking onset and unintentional injury involvement after drinking, Journal of the American Medical Association (In Press).

Koch G.G., Freeman D.H. and Freeman J.L. (1975) Strategies in the multi variate analysis of data from complex surveys, International Statistical Review. 43, 59-78.

Lui S., Seigel P., Brewer R., Mokdad A, Sleet D., and Serduda M., (1997) Prevalence of alcohol impaired driving: results from a national self reported survey, Journal of the American Medical Association. 272, 2, 123-125.

Massey, J.T., Parsons, V.L., and Tadros W. (1989) Design and estimation for the national health interview survey, 1985 - 1994, Vital and Health Statistics Report Series 2(10), National Center for Health Statistics, U.S. Department of Health and Human Services, Hyattsville, MD

National Highway Traffic Safety Administration (1996) National Survey of Drinking and Driving Attitudes and Behavior, DOT HS 808 438. U.S. Department of Transportation, Washington, DC.

National Highway Traffic Safety Administration (1999) Traffic Safety Facts, 1998: Alcohol, DOT HS 808 950. U.S. Department of Transportation, Washington, DC. 
O' Malley, P. and Wagenaar, A. (1991) Effects of minimum drinking age laws on alcohol use, related behaviors, and traffic crash involvement among American youth., $J$. of Alcohol Studies. 52, $478-491$.

O'Malley, P.M. and Johnston, L.D. (1999) Drinking and driving among high school seniors. American Journal of Public Health. 89, 5, 678-684.

Shah, B.V., Barnwell, B.G., and Bieler, G.S. (1996) SUDAAN User's Manual, Release 7.0, Research Triangle Institute, Research Triangle Park, NC.

U.S. Department of Health and Human Services Office of the Secretary (1997) Ninth special report to the U.S. Congress on alcohol and health June 1997, Page $19 \mathrm{NIH}$ Publication Number 97-4017, NIH, NIAAA.

Zador P., Krawchuck S., and Voas R. (2000) Alcohol related relative risk of driver fatalities and driver involvement in fatal crashes in relation to driver age and gender, Journal Studies on Alcohol, 61: 387-395. 
Figure 1

Drove a Motor Vehicle After Drinking Too

Percent Much According to Age of Drinking Onset

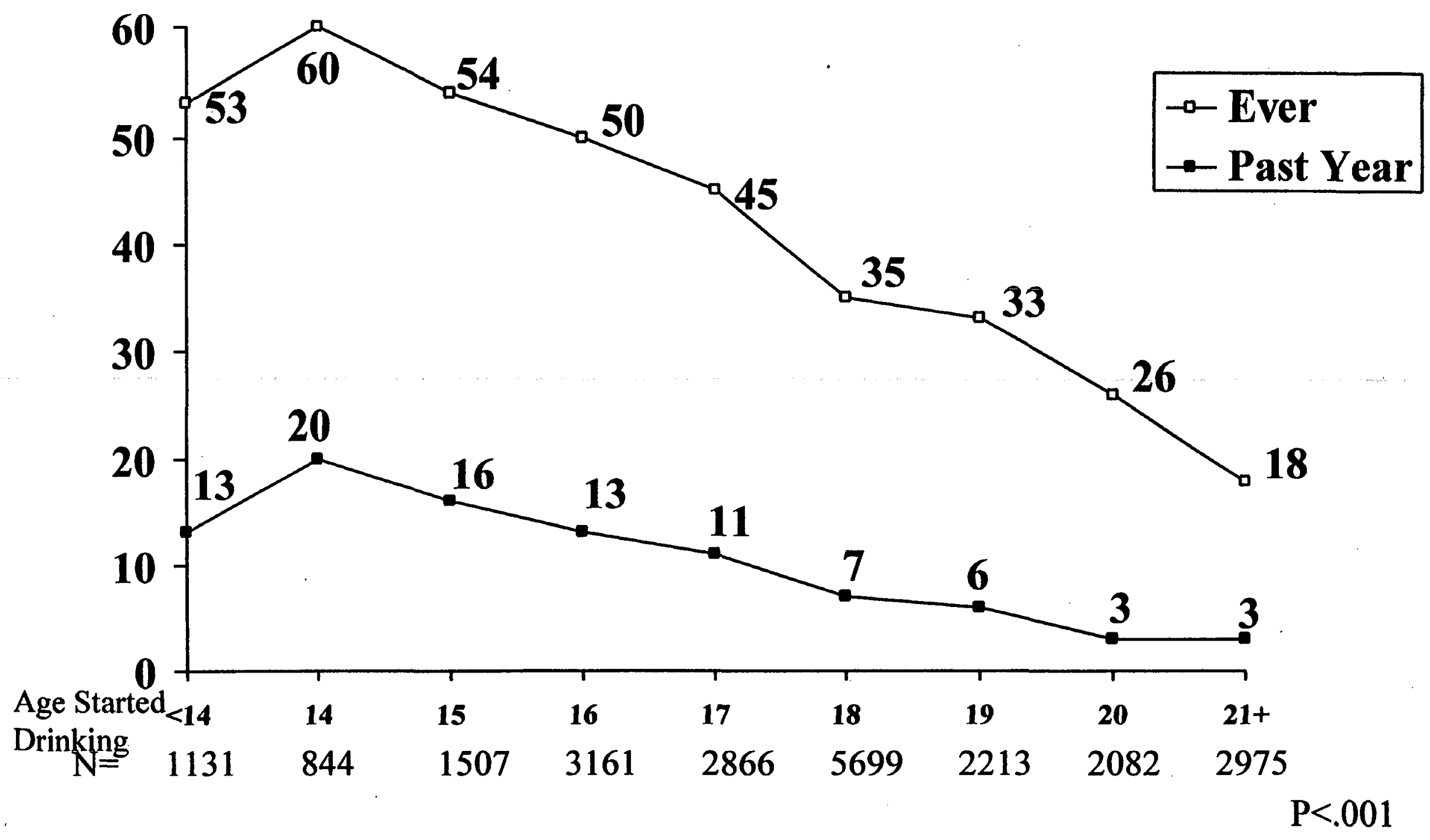


Figure 2

In a Motor Vehicle Crash Because of

Drinking According to Age of Drinking Onset

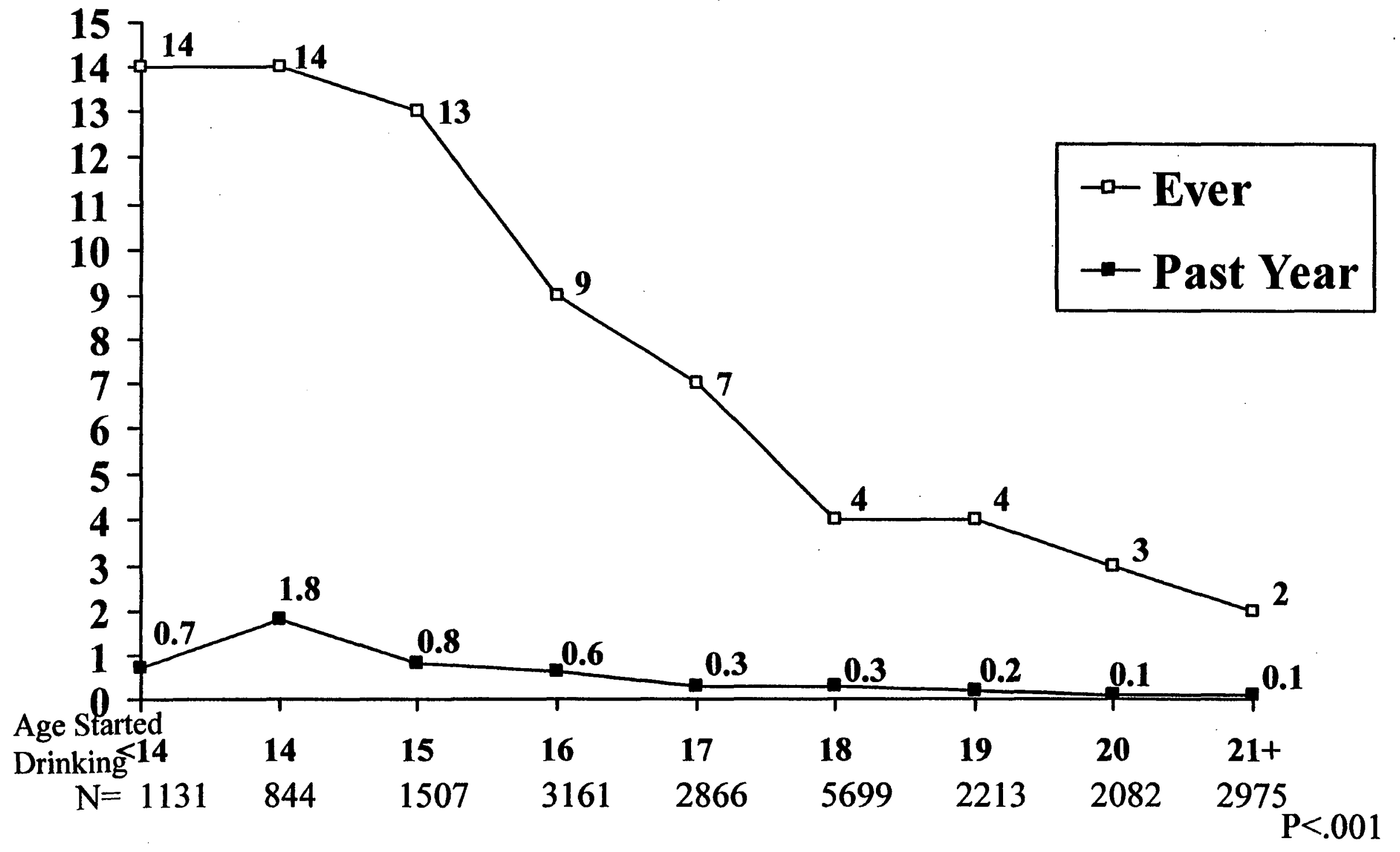




\section{Figure 3: Drove After Drinking Too Much According to Age of Drinking Onset (NLAES)}

Odds Ratio and

Confidence Intervals
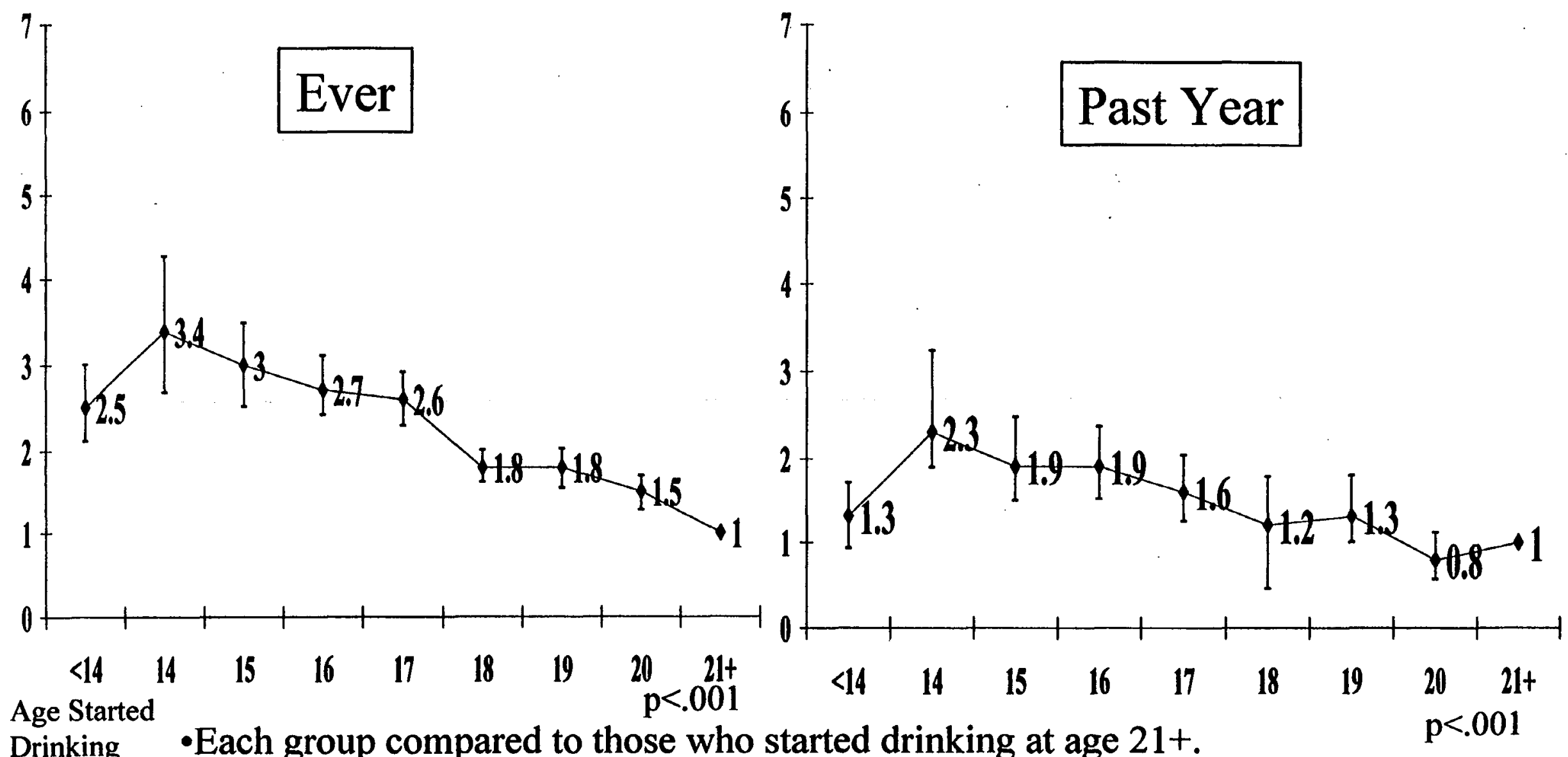

Age Started

Drinking

-Each group compared to those who started drinking at age $21+$.

20
$\mathrm{p}<.001$

-Controlling for: ever/past year/never alcohol dependent, age, sex, race/ethnicity, education, marital status, smoking, and illicit drug use. 


\section{Figure 4: In a Motor Vehicle Accident Because of Drinking Too Much According to Age of Drinking Onset (NLAES)}
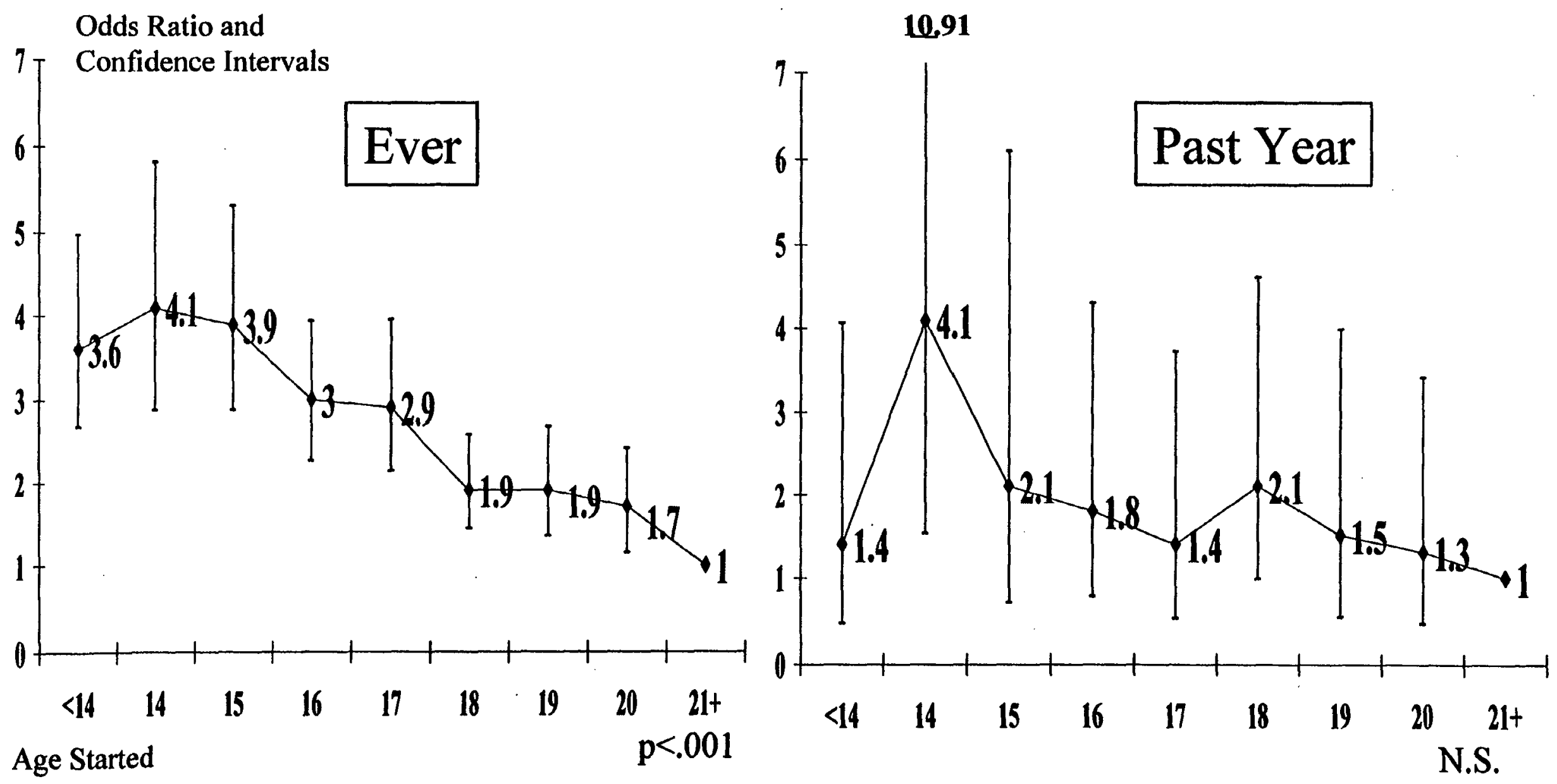

Age Started

Drinking $\quad$ Each group compared to those who started drinking at age $21+$.

-Controlling for: ever/past year/never alcohol dependent, age, sex, race/ethnicity, education, marital status, smoking, and illicit drug use. 


\section{Figure 5: In a Motor Vehicle Crash After Drinking Too Much According to Age of Drinking Onset (Subjects Who Were Never Alcohol Dependent)}

Odds Ratio and

Confidence Intervals

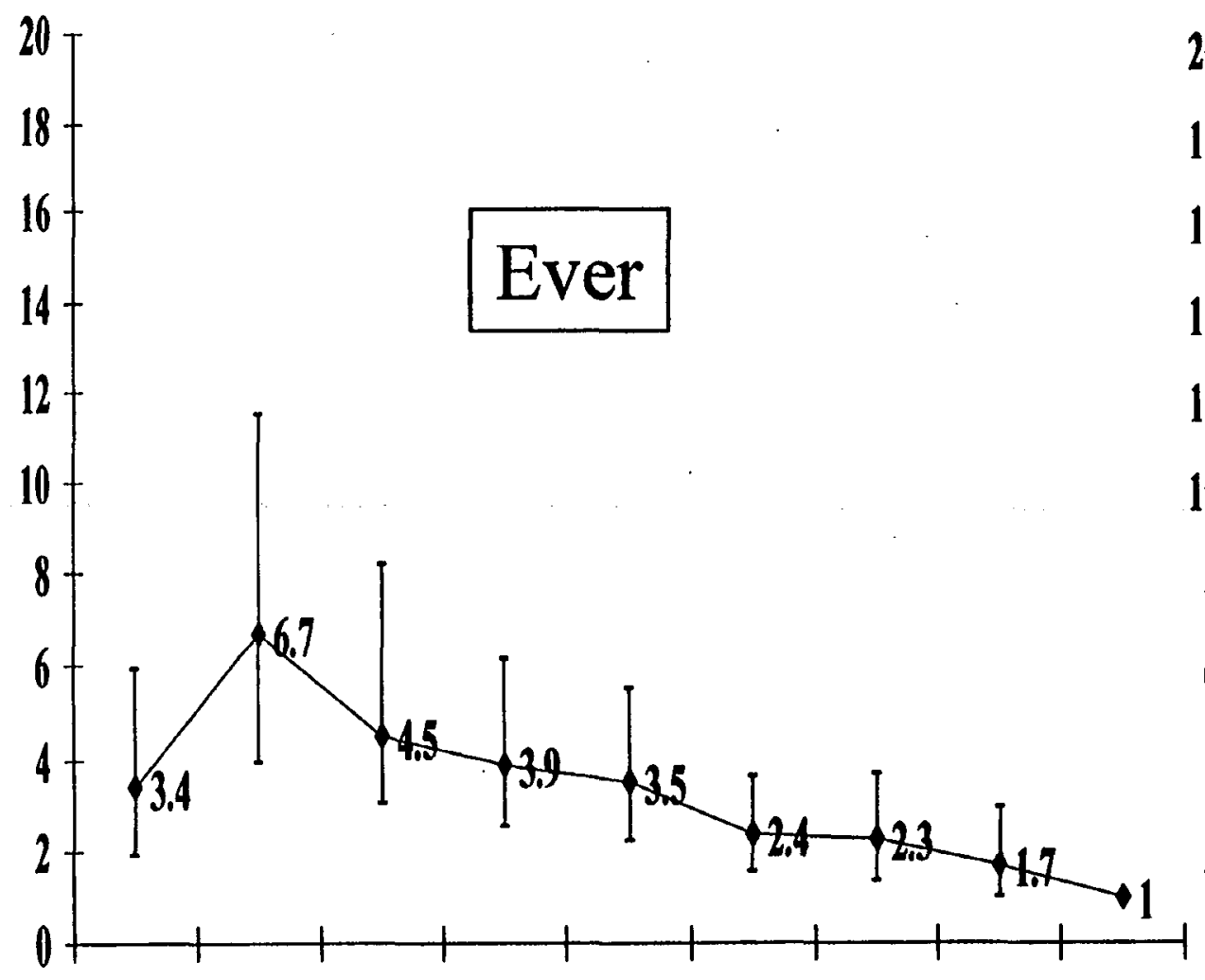

$\begin{array}{lllllllll}<14 & 14 & 15 & 16 & 17 & 18 & 19 & 20 & 21+\end{array}$
80.1

55.8

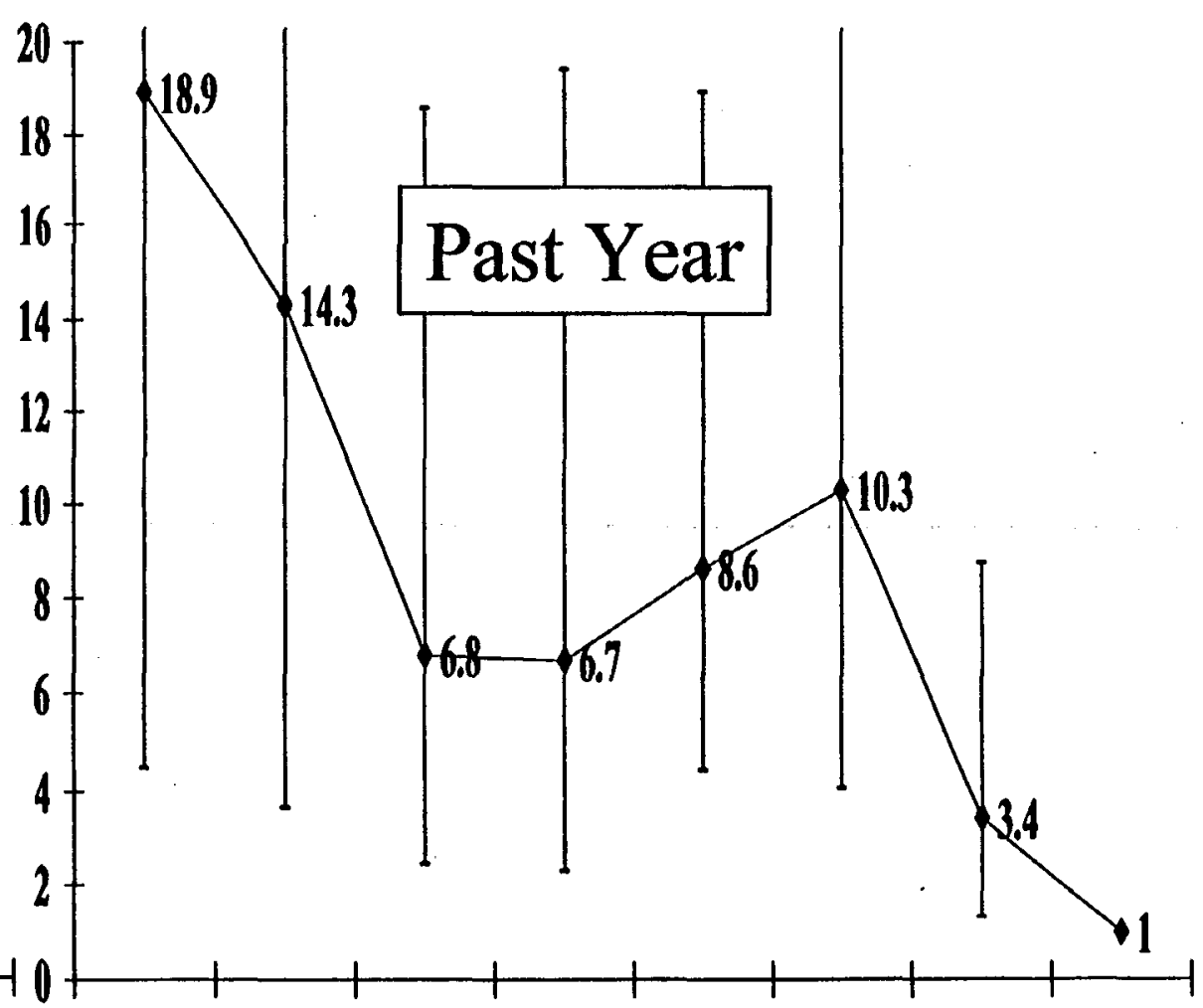

$\begin{array}{llllllll}14 & 15 & 16 & 17 & 18 & 19 & 20 & 21+\end{array}$

Age Started Drinking -Controlling for: age, gender, racepethnicity, education, marital status, smoking, and drug use. -Each group compared to those who started drinking at age $21+$. 


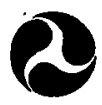

U.S. Department of Transportation

National Mighway

Truffic Sofoty

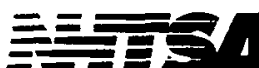

Administrefion

Poopla saving Pecpio

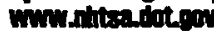

DOT HS 809188

January 2001 